\title{
The restorative effects of adipose-derived mesenchymal stem cells on damaged ovarian function
}

\author{
Yuji Takehara, Akiko Yabuuchi, Kenji Ezoe, Tomoko Kuroda, Rie Yamadera, Chiaki Sano, Nana Murata, Takuya Aida, \\ Ken Nakama, Fumihito Aono, Naoki Aoyama, Keiich Kato and Osamu Kato
}

The clinical application of human adipose-derived mesenchymal stem cells (MSCs) as treatment for intractable diseases or traumatic tissue damage has attracted attention. To address the ability of reactivating injured ovaries, we prepared a rat model with damaged ovaries by using an anticancer agent, cyclophosphamide (CTX). We then investigated the restorative effects on ovarian function and the safety of adipose-derived MSCs (A-MSCs). MSCs were shown to be capable of inducing angiogenesis and restoring the number of ovarian follicles and corpus lutea in ovaries. No deformities, tumor formation or deaths were observed in F1 and F2 rats, indicating that the local injection of MSCs into the ovary did not have any obvious side effects. In addition, the localization of the Y chromosome was investigated using the fluorescent in situ hybridization method by injecting male A-MSCs into the ovaries; as a result, the $\mathrm{Y}$ chromosomes were localized not in the follicles, but in the thecal layers. ELISA revealed that A-MSCS secreted higher levels of vascular endothelial cell growth factor (VEGF), insulin-like growth factor-1 (IGF-1) and hepatocyte growth factor (HGF) than tail fibroblast cells. Quantitative real-time PCR and immunohistochemistry showed that higher expression levels of VEGF, IGF-1 and HGF were observed in CTX-treated ovaries after A-MSC transplantation. These findings suggest that MSCs may have a role in restoring damaged ovarian function and could be useful for regenerative medicine.

Laboratory Investigation (2013) 93, 181-193; doi:10.1038/labinvest.2012.167; published online 19 November 2012

KEYWORDS: adipose-derived mesenchymal stem cells; in vitro fertilization; ovarian dysfunction; premature ovarian failure; stem cell transplantation

Since the world's first in vitro fertilization baby was born in $1978,{ }^{1}$ the realm of fertility treatment has changed dramatically. Artificial insemination, which was previously considered to be the ultimate therapy, has essentially replaced in vitro fertilization (IVF). Advanced technology, such as intracytoplasmic sperm injection (ICSI), ${ }^{2}$ the freezing of oocytes and fertilized embryos, ${ }^{3,4,5,6,7}$ assisted hatching ${ }^{8}$ and pre-implantation genetic diagnosis, ${ }^{9}$ have been applied widely. Even a patient with azoospermia, if testicular resection can reveal the presence of intratesticular sperm, ${ }^{10,11}$ can father a baby using ICSI. ${ }^{12,13}$ What was, in the past, 'impossible' is now quite 'possible'. Some people, however, cannot conceive, even with the use of all the existing ancillary technologies. Such situations occur when germ cells are not present in the testis or when ICSI cannot be performed because of the absence of mature sperm as a result of maturation arrest. In women, senescent oocytes as a result of aging reduce the pregnancy rate; furthermore, when women reach menopause, oocyte retrieval for IVF tends to be unsuccessful because of dysfunction of ovarian follicle growth. Various reports have discussed whether germ cells can be differentiated and induced directly from stem cells, such as embryonic stem (ES) ${ }^{14,15}$ and induced pluripotent stem (iPS) cells. ${ }^{16,17}$ Additional research is required to determine whether allogenic ES cells or autologous iPS cells are safe and effective before clinical applications in humans can be considered. On the other hand, there are high expectations for therapeutic self-derived mesenchymal stem cells (MSCs). An increasing number of reports are being published regarding their use in regenerative medicine; however, MSCs are incapable to be induced directly into germ cells. Specifically, cardiac muscle cell differentiation from MSCs has been demonstrated, including cord bloodderived MSCs, ${ }^{18}$ MSCs derived from chorionic plate of the placenta ${ }^{19}$ and menstrual blood derived $\mathrm{MSCs}^{20}{ }^{20}$ which are thought to be effective for patients whose bone marrow cannot be obtained but who require MSCs. MSC culture using fetal bovine serum (FBS)-free media has been successful, ${ }^{21}$ and consequently, its application in humans is thought to be possible. Another paper described the

Kato Ladies Clinic, 7-20-3 Nishishinjuku, Shinjuku-ku, Tokyo, Japan

Correspondence: Dr Y Takehara, MD, PhD or O Kato, MD, Kato Ladies Clinic, 7-20-3 Nishishinjuku, Shinjuku-ku, Tokyo 160-0023, Japan.

E-mail: y-takehara@towako-kato.com (YT) or o-kato@towako-kato.com (OK)

Received 14 May 2012; revised 4 October 2012; accepted 21 October 2012 
differentiation capacity into cardiac muscle cells and the tolerance to immunity by establishing MSCs from human amnion, ${ }^{22}$ suggesting that the potential efficacy of MSCs regardless of their origins.

Taken into account a report published in 2008 by $\mathrm{Fu}$ et $a l,{ }^{23}$ describing the effectiveness of bone marrow-derived MSCs (BM-MSCs) after their transplantation into ovaries, ${ }^{23}$ we hypothesized that adipose-derived MSCs may also retain the ability of restoring the ovarian function. Therefore, in this study, we conducted experiments wherein adipose-derived MSCs were transplanted into damaged ovaries and the safety and the restorative effect on ovarian function were evaluated in rats and mice. Our experiments with adipose-derived MSC transplantation leads us to speculate whether human abdominal subcutaneous adipose-derived MSCs could improve ovarian function and enhance the success rate of in vitro fertilization for in the future.

\section{MATERIALS AND METHODS \\ Experimental Animals}

Wistar-Imamichi female rats (7-8 weeks old; Institute of Animal Reproduction) with two or more 4-day reproductive cycles and C57BL/6J female mice (5 weeks old; Institute of Animal Reproduction) were used for the experiments. All animals were housed in an isolator for experimental animals (Innorack ${ }^{\mathbb{R}}$ IVC; Oriental Giken) under a $12 \mathrm{~h}$ light and dark cycle and were fed ad libitum.

\section{Isolation of Rat and Mouse Adipose-Derived MSCs}

Rats and mice were euthanized with $\mathrm{CO}_{2}$, their abdomens were cut open and the adipose tissues were removed. After the adipose tissues were washed with saline solution, all the tissues were collected and incubated in DMEM/F12 medium containing $0.2 \%$ collagenase (Wako: STE3315), DMEM/F12 (Gibco: 891768 ) and 1\% penicillin-streptomycin mixed solution (GIBCO: 15140) at $37^{\circ} \mathrm{C}$ for $40 \mathrm{~min}$. After the cell suspension was centrifuged (at $630 \mathrm{~g}$ for $10 \mathrm{~min}$ ), the fat layer found in the upper layer and the culture solution layer found in the middle layer were removed, and the stromal vascular fraction (SVF) obtained as a sediment was collected. The culture medium for incubation, which consist of DMEM/F12 (Gibco: 891768), 10\% FBS (Hyclone: KUE33539), 1\% penicillin-streptomycin mixed solution (GIBCO: 15140), 1\% L-glutamine solution (Gibco: 891743), 1\% non-essential amino-acid (Gibco: 879514), was added to the SVF to be suspended, and the SVF suspension was filtered through a $100 \mu \mathrm{m}$ filter. After adding saline solution to wash away the collagenase in the cell suspension, the suspension was centrifuged (at $280 \mathrm{~g}$ for $5 \mathrm{~min}$ ) and the supernatants were removed. The cell suspension was adjusted with the culture medium and was partially co-stained with Hoechst $(10 \mu \mathrm{g} /$ $\mathrm{ml})$ and propidium iodide $(10 \mu \mathrm{g} / \mathrm{ml})$ in saline solution to check cell viability. The living cells were seeded at the concentration of 5000 cells $/ \mathrm{cm}^{2}$ and were incubated at $37^{\circ} \mathrm{C}$ in $5 \% \mathrm{CO}_{2}$ and $95 \%$ air. The culture media were exchanged every 3 days. The cells were passed when they reached to $80-90 \%$ confluence. Excess cells were cryopreserved in a cell freezing medium (Lymphotec: CS-02-001) at $5 \times 10^{6}-1 \times 10^{7}$ cells/ml per tube.

\section{Isolation of Rat BM-MSCs}

Femurs were collected and washed in PBS (-) with $1 \%$ penicillin-streptomycin solution. Both ends of the femurs were cut off using a bone cutter. A $10 \mathrm{ml}$ syringe with a $16-\mathrm{G}$ needle was filled with PBS (-) with $1 \%$ penicillinstreptomycin to flush the femoral bone marrow, and the bone marrow cells were collected. The collected bone marrow was transferred to a $50 \mathrm{ml}$ tube and centrifuged at $280 \mathrm{~g}$ for $5 \mathrm{~min}$. After the supernatants were removed, the precipitated cells were washed three times in PBS (-) with $1 \%$ penicillin-streptomycin solution. As with the adipose-derived MSCs, the cell suspension was subsequently adjusted with the same culture medium as adipose-derived MSCs (AMSCs), and after examining cell viability as described above, living cells were seeded at $5000 \mathrm{cells} / \mathrm{cm}^{2}$ and were cultured at $37^{\circ} \mathrm{C}$ in $5 \% \mathrm{CO}_{2}$ and $95 \%$ air.

\section{Isolation of Rat Tail Fibroblast Cells}

Rat tail tips were collected, and washed in PBS ( - ) with $1 \%$ penicillin-streptomycin solution. After cutting into small pieces, they were treated in DMEM/F12 media with $0.2 \%$ collagenase and $1 \%$ penicillin-streptomycin mixed solution at $37^{\circ} \mathrm{C}$ for $1 \mathrm{~h}$ to dissociate cells. The media with dissociated cells were centrifuged and the supernatant was removed. The cell pellets were suspended in culture media as same as A-MSC culture media and then filtered through a $100 \mu \mathrm{m}$ filter. They were then centrifuged and the supernatant was removed. After suspending cell pellets in culture media, living cells were counted as described above and cultured at 5000 cells $/ \mathrm{cm}^{2}$ at $37{ }^{\circ} \mathrm{C}$ in $5 \% \mathrm{CO}_{2}$ and $95 \%$ air.

\section{FACS Analysis Using Cell Surface Antigen Markers}

Cell surface antigen marker expression among established cell lines of rat and mouse adipose tissue-derived MSCs, rat BM-MSCs and rat tail fibroblast cells was analyzed by FACS. For the antibodies, FITC- or Pacific blue-conjugated monoclonal antibodies such as CD29 (LifeSpan: 19427; BioLegend: 102203), CD34 (Santa Cruz Biotechnology: B1810; BioLegend: 128603), CD44 (Abcam: 957673; BioLegend: 103005), CD45 (AbD Serotec: 010; BioLegend: 103107), CD73 (BD: 60140), CD105 (Millpore: 05-1424) and CD90 (Abcam: 876573) were used. The results were analyzed using an Attune Acoustic Focusing Cytometer (Applied Biosystems).

\section{Preparation of Infertility Model Rats and Mice with Ovarian Failure}

Wistar-Imamichi female rats (7-8 weeks old) with two or more 4-day reproductive cycles were used. After weigh- 
ing the rats, cyclophosphamide (CTX; Sigma: C0768) was administered at $50 \mathrm{mg} / \mathrm{kg}$ by intraperitoneal injection, regardless of the reproductive cycle. Then, CTX was administered at $8 \mathrm{mg} / \mathrm{kg}$ daily for 13 consecutive days, for a total of 14 days. As for C57BL/6J female mice (5 weeks old), single injection of CTX $(200 \mathrm{mg} / \mathrm{kg})$ was administered intraperitoneally.

\section{Procedure for Cell Transplantation into Rat and Mouse Ovaries}

For the cell transplantation, a glass capillary injection pipette with a 30-G needle was used. CTX-treated rats and mice were intraperitoneally injected with Avertin (Sigma-Aldrich) at a dose of $250 \mathrm{mg} / \mathrm{kg}$, and their skin and muscle layers were cut open after shaving in a decubitus position. The ovary was exteriorized and fixed using forceps (Figure 1a (A)), and a total of $2 \times 10^{6}$ cells per $10 \mu \mathrm{l}$ saline solution of rat A-MSCs, BM-MSCs and tail fibroblast cells were transplanted into rat ovary 15 days after initial CTX injection using an injection pipette (Figure 1a (B)). A measure of $10 \mu \mathrm{l}$ (for rats) and $5 \mu \mathrm{l}$ (for mice) of saline solution were sham injected into ovaries to serve as a control. No leakage was visually observed after transplantation (Figure 1a (C)).

\section{Assessment of Ovarian Function by Comparison of Ovarian Follicle and Corpus Luteum Counts}

At 8 weeks after cell transplantation, rats and mice were euthanized and left (cell transplanted) and right (nontransplanted) ovaries were removed for fixation to prepare the sections. A histological analysis was performed using a conventional method that included the trimming of the largest ovarian area, slicing it into a $5 \mu \mathrm{m}$ thickness to prepare the sections and staining with hematoxylin and eosin (HE). The ratio of the number of ovarian follicles and corpus lutea in left side ovaries to the right side ovaries was calculated and compared between each group $(n=10)$.

\section{Assessment of Functional Improvement and Safety by Comparison of Litter Size}

To examine the improvement in ovarian function and the safety of cell transplantation, we compared the litter sizes obtained by natural mating after the transplantation of the established A-MSCs and BM-MSCs into the both side of

a
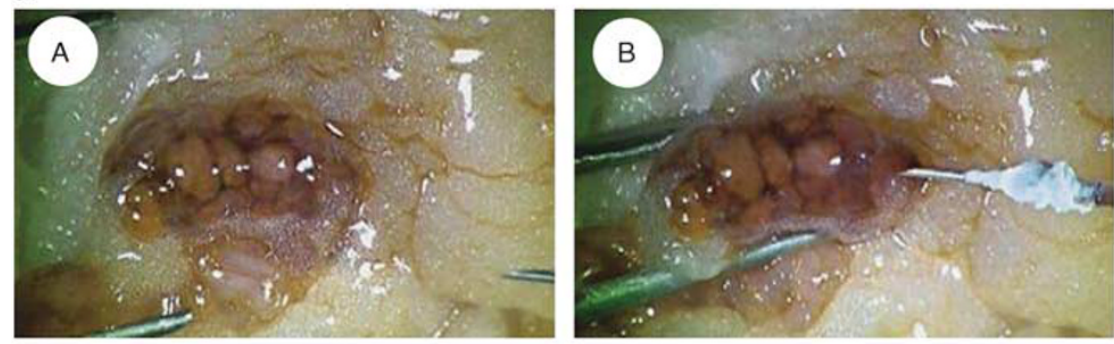

b
Adipose

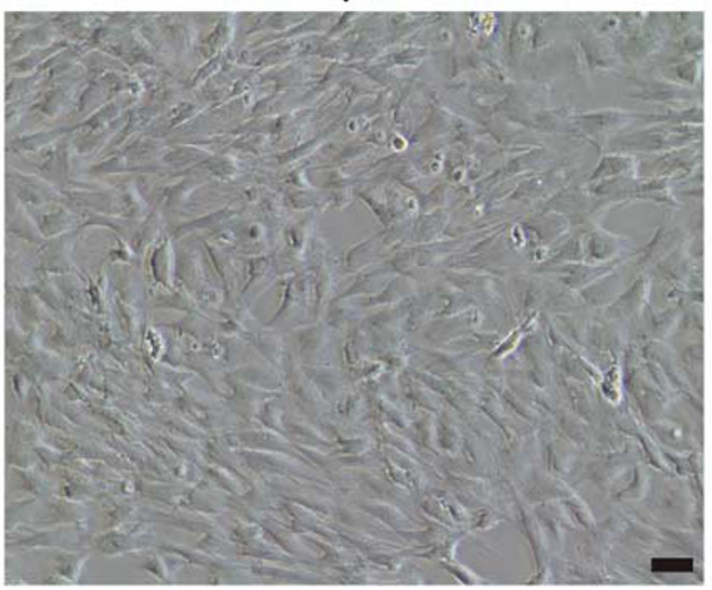

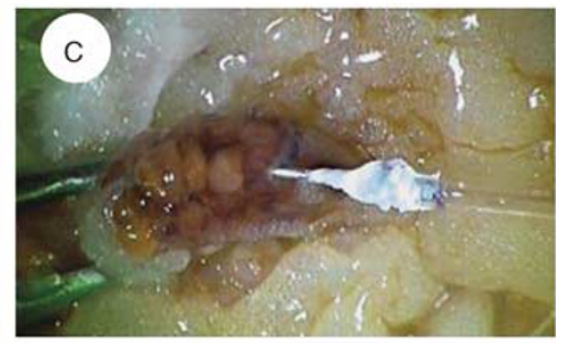

BM

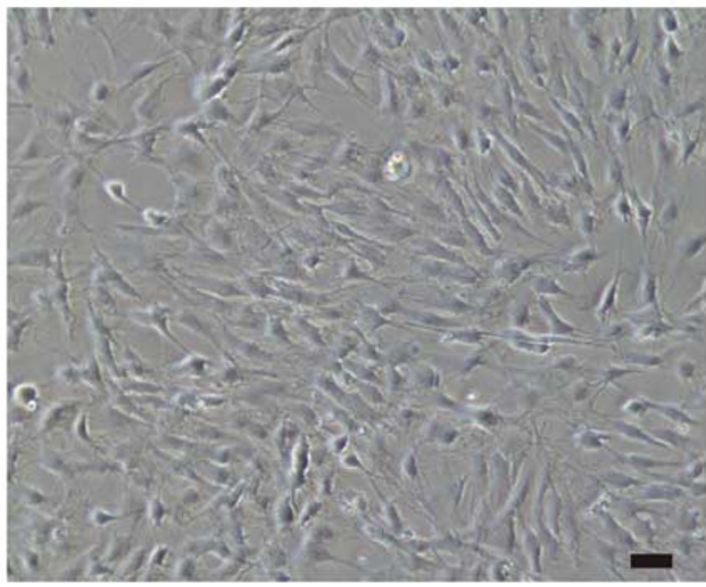

Figure 1 Characterization of adipose-derived mesenchymal stem cells (A-MSCs) and bone marrow-derived MSCs (BM-MSCs) and the procedure for MSC transplantation into ovaries. (a) The procedure for MSC transplantation into ovaries. (A) A sufficient visual field was secured by observing the ovarian blood vessels using a stereomicroscope and the removal of excess fat. (B) An A-MSC/BM-MSC suspension $\left(2 \times 10^{6}\right.$ cells/10 $\mu$ l) was injected into the ovary, which was held in place with forceps. (The above figure shows the indigo carmine injection.) (C) No leakage was visually observed after the injection. (b) The morphology of cultured A-MSCs and BM-MSCs. Adipose: A-MSCs; BM: BM-MSCs. Scale bar $=40 \mu \mathrm{m}$. (c) Fluorescence cell sorting (FACS) analysis of A-MSCs, BM-MSCs and tail fibroblast cells stained with cell surface antigen markers of MSCs. BM: BM-MSCs; adipose: A-MSCs; fibroblast: tail fibroblast cells. 
c
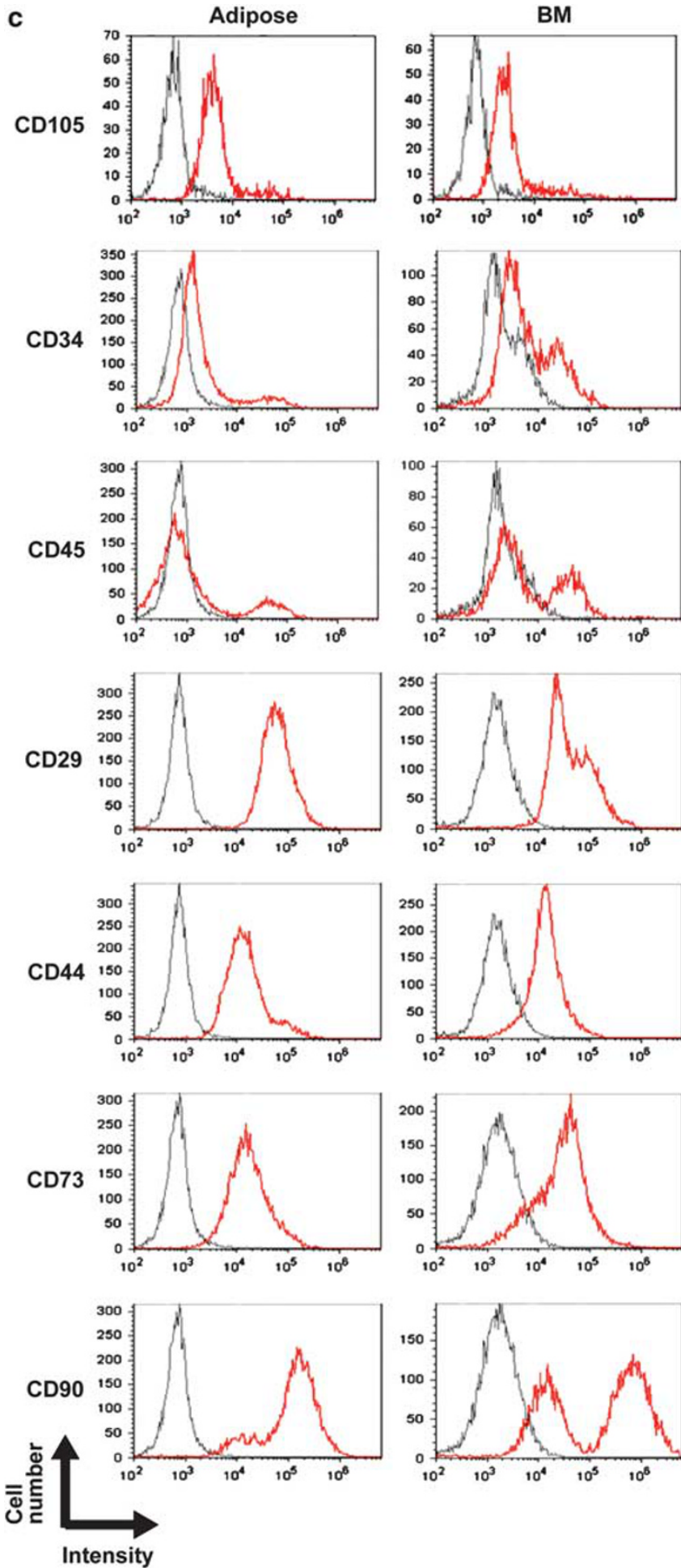

BM
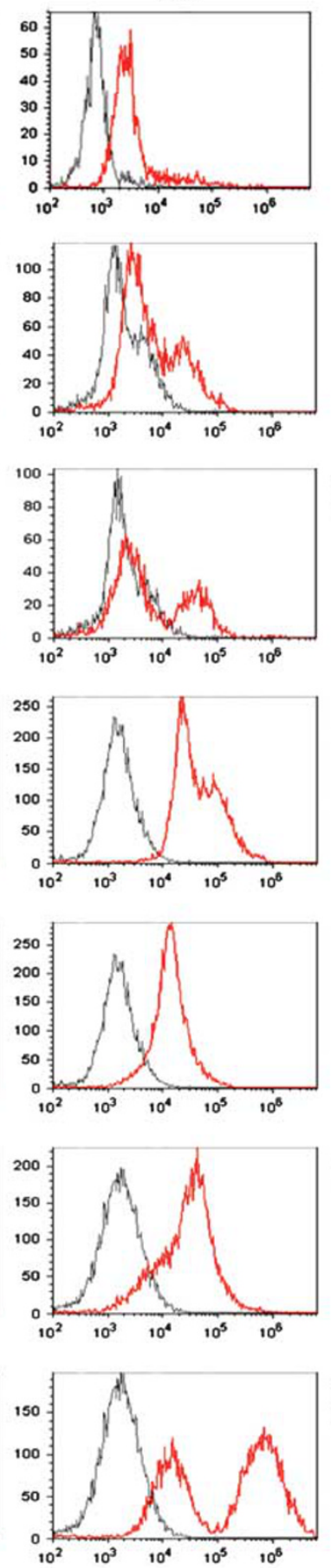
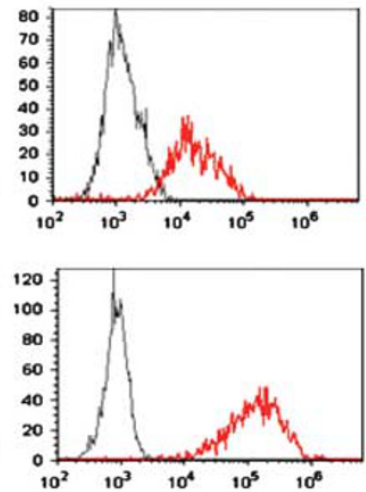

Fibroblast
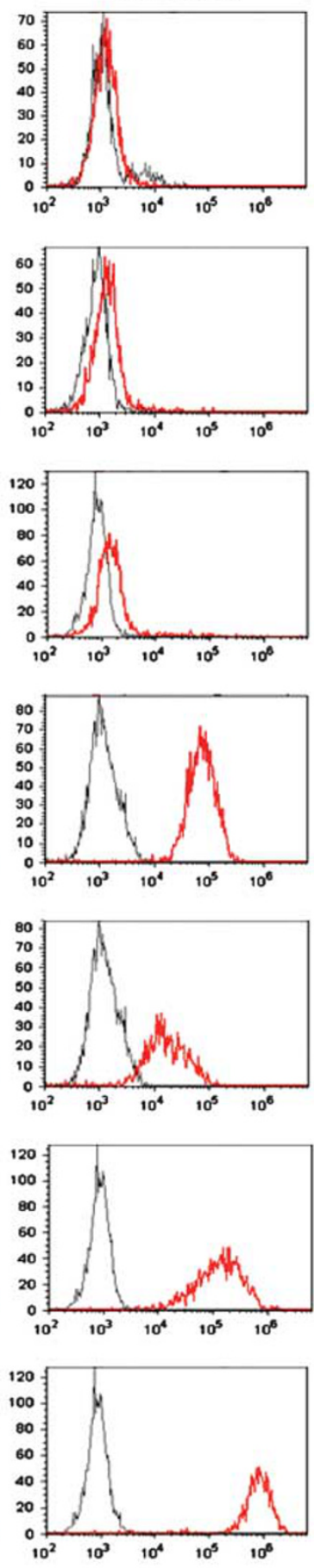

Figure 1 Conintued

ovaries having decreased ovarian function induced by the CTX. At 8 weeks after MSC transplantation, the female rats, which were found to be in proestrus based on a vaginal smear test, were put into the same cage with male rats for natural mating. The subsequent litters that were born (F1) were examined for serious adverse effects by cell transplantation. F1 litter size were compared between CTX non-administration $($ CTX -$)$ group and the groups in which CTX administration 
$(\mathrm{CTX}+)$ with saline solution sham injection, A-MSCs (P0 and P2) and BM-MSCs transplantation $(n=5)$. Furthermore, litters (F2) obtained by natural mating between female rats selected from the F1 generation born in each group and male rats selected in the same way from the F1 generation were compared and examined for serious side effects by cell transplantation with the control group.

\section{Measurement of Cytokine Secretion from A-MSCs and Tail Fibroblast Conditioned Media}

To analyze the cytokine secretion from A-MSCs and tail fibroblast cells, the concentrations of vascular endothelial cell growth factor (VEGF), insulin-like growth factor-1 (IGF-1), hepatocyte growth factor (HGF) and estradiol in the cell conditioned media were measured by EIA.

The conditioned media for rat and mouse A-MSCs and rat tail fibroblast cells were prepared as follows:

The cells were cultured on the dish at concentrations of $1 \times 10^{5} / \mathrm{ml}$. After $24 \mathrm{~h}$ of cultivation under individual culture conditions, the dishes were replaced with DMEM/F12 media without any serum or growth factors and were incubated for $72 \mathrm{~h}$. The media were collected and centrifuged at $280 \mathrm{~g}$ for $5 \mathrm{~min}$ and the supernatant were served as conditioned media for EIA. As for EIA kits, the Rat VEGF Immunoassay (Quantikine: RRV00), VEGF mouse ELISA kit (Abcam: ab100751), Rat IGF-1 Immunoassay (Quantikine: MG100), IGF-1 mouse ELISA kit (Abcam: ab100695), Rat HGF EIA (Institute Immunology), HGF mouse ELISA kit (Abcam: ab100687) and Estradiol EIA kit (Cayman Chemical Company) was used according to the manufacturer's instruction. The ELISA plates were read at iMark microplate absorbance reader (Bio-Rad).

\section{Growth Factor Administration and A-MSC Transplantation into Mouse Ovaries}

To assess the effect of growth factors on damaged ovaries induced by CTX, VEGF, HGF, IGF-1 and mouse A-MSCs were administered into mouse ovaries. The dose of these growth factors were determined by the result of the cytokine secretion in mouse A-MSC conditioned media by ELISA. A measure of $780 \mathrm{pg}$ and $7.8 \mathrm{ng} / 5 \mu \mathrm{l}$ saline of VEGF (Santa Cruz Biotechnology: sc-4571), $590 \mathrm{pg}$ and $5.9 \mathrm{ng} / 5 \mu \mathrm{l}$ saline of HGF (R\&D Systems: $2207-\mathrm{HG} / \mathrm{CF}$ ), $150 \mathrm{pg}$ and $1.5 \mathrm{ng} / 5 \mu \mathrm{l}$ saline of IGF-1 (R\&D Systems: 791-MG) or a combination of these three growth factors were administered into mouse left ovaries. And, a total of $5 \times 10^{4}, 5 \times 10^{5}$ and $5 \times 10^{6}$ cells $/ 5 \mu \mathrm{l}$ saline solution of mouse A-MSCs were transplanted into left ovary 3 days after CTX injection. Mice were euthanized 8 weeks after administration and ovaries were collected and fixed. HE section slides were made as described above. The ratio of the number of ovarian follicles and corpus lutea in left side ovaries to the right side ovaries was calculated and compared between each growth factor-administered groups and A-MSC-transplanted groups.

\section{Immunohistochemistry}

To investigate the angiogenesis and cytokine expression in ovaries after A-MSC transplantation, the ovarian sections were immunostained for CD34, VEGF, IGF-1 and HGF antibodies. The ovarian sections were deparaffinized with xylene and hydrated using an ethanol gradient. The hydrated sections were washed in 3\% hydrogen peroxide in methanol for $20 \mathrm{~min}$ at room temperature and blocked in PBS (Sigma) containing 3\% BSA (Sigma) for $30 \mathrm{~min}$. As the primary antibodies, rat anti-CD34 antibody (Abcam: ab8158, diluted 1:100), rabbit anti-HGF antibody (Santa Cruz Biotechnology: sc-7949, diluted 1:50), rabbit anti-VEGF antibody (Santa Cruz Biotechnology: sc-9047, diluted 1:50) and rabbit antiIGF-1 antibody (Abnova Corporation: PAB19107, diluted 1:50) were used for the reaction at $4{ }^{\circ} \mathrm{C}$ for $16 \mathrm{~h}$. As the secondary antibody for HGF, VEGF and IGF-1, goat antirabbit IgG antibody conjugated to biotin (Santa Cruz Biotechnology: sc-2047, diluted 1:500) was used for the reaction at room temperature for $60 \mathrm{~min}$ and was stained using the DAB Substrate Kit (Invitrogen: 00-2014). Hematoxylin was used to co-stain the sections. And as for CD34, Alexa Fluor 594 rabbit anti-rat IgG antibody (Invitrogen: A21211, diluted 1:500) was selected as a secondary antibody and treated at room temperature for $3 \mathrm{~h}$. All sections were mounted with HistoMount Mounting Solution (Invitrogen: 00-8030) and analyzed using BIOREVO BZ-9000 (Keyence).

\section{Detection of Transplanted A-MSCs in Ovaries by Fluorescence in situ Hybridization}

To localize the A-MSCs transplanted into the ovaries, the male Wistar rat A-MSCs were established and were transplanted into the ovaries. At 8 weeks after the transplantation, the female rats were killed and the ovaries were taken out. The paraffin sections were prepared from the removed ovaries according to a standard method described above. The sections were deparaffinized with xylene and treated with $0.3 \% \mathrm{NP}-40 / 0.4 \times \mathrm{SSC}$ for $15 \mathrm{~min}$ at $72{ }^{\circ} \mathrm{C}$. After washing with water, the sections were treated with $0.5 \%$ pepsin for $30 \mathrm{~min}$ at $37^{\circ} \mathrm{C}$ and fixed again in Carnoy's solution (Carnoy:methanol and acetic acid=3:1). The fluorescent in situ hybridization (FISH) method was used to detect the distribution of cells exhibiting male $\mathrm{X}$ and $\mathrm{Y}$ chromosomes in the ovarian tissues. A FISH probe (Chromosome Science Laboratory) was hybridized to the centromere region of the $\mathrm{X}$ and $\mathrm{Y}$ chromosomes of rats overnight at $37^{\circ} \mathrm{C}$ after heat denatured for $5 \mathrm{~min}$ at $75^{\circ} \mathrm{C}$. After washing in $0.3 \% \mathrm{NP}-40 /$ $0.4 \times$ SSC for 5 min at $72{ }^{\circ} \mathrm{C}$ and then in $0.1 \% \mathrm{NP}-40 / 2 \times$ SSC for $1 \mathrm{~min}$ at room temperature, the tissues were counterstained with DAPI (4'-6-diamidino-2-phenylindole, $150 \mathrm{ng} /$ $\mathrm{ml})$.

\section{Quantitative RT-PCR Assay}

Rat A-MSC, tail fibroblast cell-transplanted rats were euthanized at their proestrus, determined by vaginal smear test and the ovaries were taken out. Total RNA was extracted from 
b

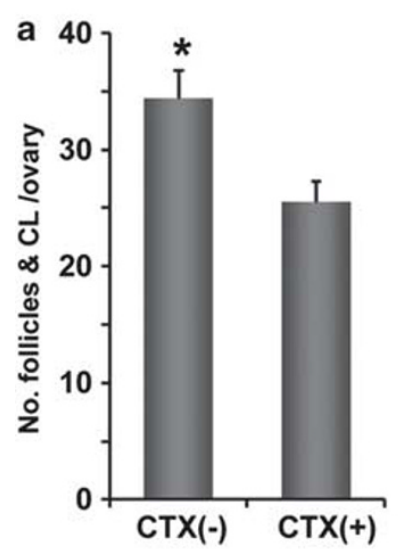

b

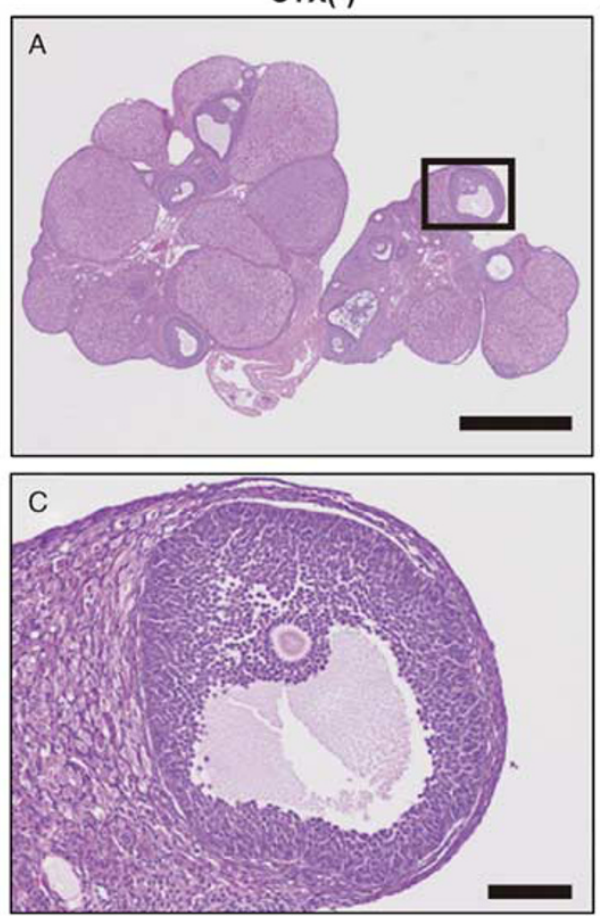

CTX(+)
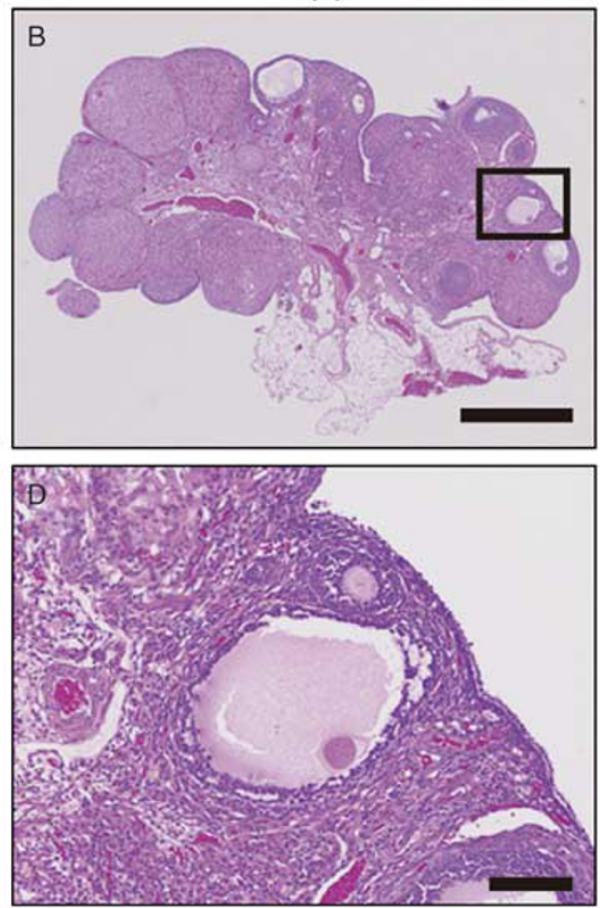

Figure 2 Histological analysis of rat ovary after the administration of cyclophosphamide (CTX). (a) Comparison of the numbers of follicles and corpus lutea $(\mathrm{CL})$ in ovaries between $\mathrm{CTX}$-non-treated rats and CTX-treated rats (*significantly different, $P<0.05)$. (b) Hematoxylin- and eosin- (HE) stained ovaries of CTX-non-treated rats (A, C) and CTX-treated rats (C, D). (A, B) Scale bar $=1 \mathrm{~mm}$ and (C, D) scale bar $=200 \mu \mathrm{m}$.

an ovary of each groups using Trizol reagent (Invitrogen: 15596026) and purified using PureLink RNA mini kit (Ambion: $12183018 \mathrm{~A})$. RNA $(5 \mu \mathrm{g})$ was reverse transcribed using High capacity RNA to cDNA kit (Applied Biosystems: 4387406) to obtain cDNA. TaqMan Gene Expression Assay was selected for VEGF (Applied Biosystems: Rn01511601m1), HGF (Applied Biosystems: Rn00566673-m1), IGF-1 (Applied Biosystems: Rn00710306-m1) and StAR (Applied Biosystems: Rn00580695-m1) primers. Amplification was performed in a total volume of $20 \mu \mathrm{l}$ per reaction using TaqMan Fast Universal PCR Master Mix (Applied Biosystems: 4352042) and a StepOnePlus Real-time PCR System (Applied Biosystems). Each sample was assayed in duplicate and normalized to glyceraldehydes-3-phosphate dehydrogenase (Applied Biosystems: Rn01775763-g1). Relative quantification of gene expression was analyzed according to the standard curve method using StepOne software version 2.1 and the ratio of expression folds in left side ovaries to the right side ovaries was calculated.

\section{RESULTS}

\section{Characterization of Established BM-MSC and A-MSC Cell Lines}

The cell populations presumed to be BM-MSCs and A-MSCs were obtained from two tissues, bone marrow and adipose. Adherent cells with well-developed dendrites grew stably in both cell lines and did not show any morphological differ- ences despite the difference in their origins (Figure 1b). A cell surface marker specific to MSCs was used in flow cytometry studies, and a high purity of BM-MSCs and A-MSCs was obtained. Both BM and A-MSCs were negative for CD34 and CD45, which are negative surface antigen markers of MSCs (Figure 1c), and they were positive for CD105, CD29, CD44, CD73 and CD90, which are positive surface antigen markers of MSCs. Thus, both cell lines mainly consisted of MSCs. CD105 was negative in tail fibroblast cells.

\section{CTX Treatment Induced Damaged Ovarian Function}

To evaluate the effect of CTX on ovarian function, the number of unilateral follicles were compared between CTXnon-treated and CTX-treated rats. The mean total number of follicles and corpus lutea in CTX-non-treated and CTXtreated rats were $34.4 \pm 2.4$ and $25.5 \pm 1.8$, respectively, showing that CTX significantly decreased the number of follicles (Figure 2a). In addition, the degeneration of the follicular parenchyma was observed in HE-stained tissue samples (Figure $2 \mathrm{~b}$ ). Therefore, the administration of CTX decreased ovarian function.

\section{A-MSC Transplantation Induced Angiogenesis in CTX- Treated Ovaries}

To detect vascular endothelial cells, the number of CD34positive cells per $1 \mathrm{~mm}^{2}$ of corpus luteum was examined in corpus lutea in the ovaries using BZ Analyzer (Keyence). Rat 

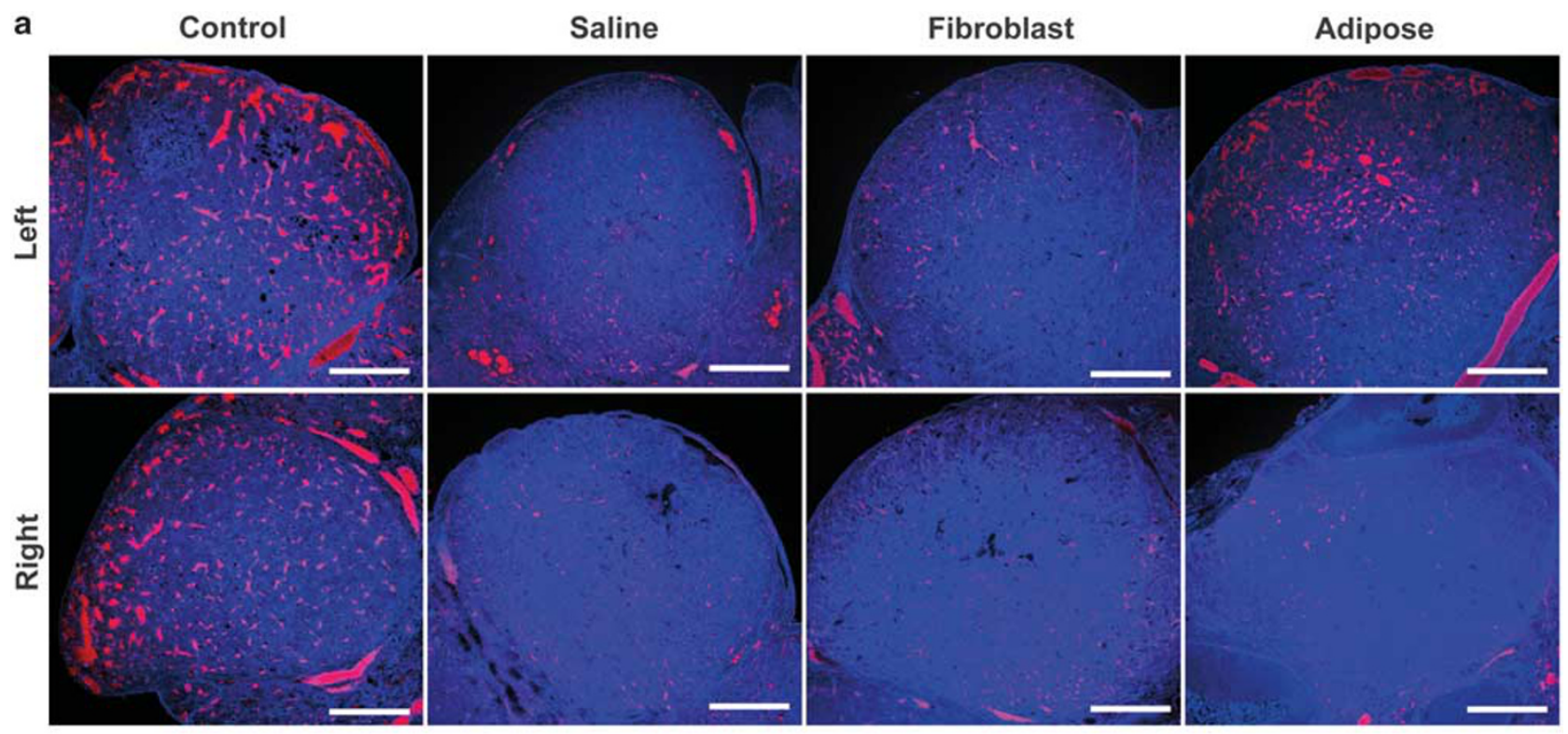

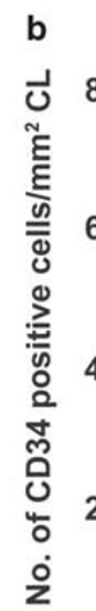
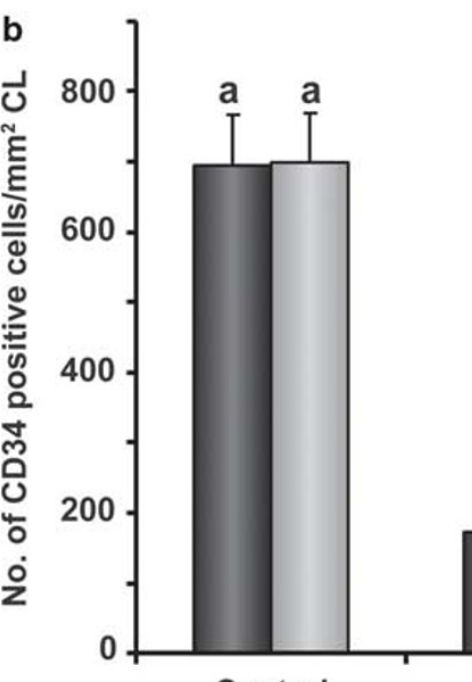

Control

Figure 3 Angiogenesis on cyclophosphamide-(CTX)-treated ovaries after adipose-derived mesenchymal stem cell (A-MSC) and tail fibroblast transplantation. (a) Immunohistochemistry (IHC) of CD34 on rat ovaries. Left, is the cell or saline administration; right, non-injected control. Fibroblast: tail fibroblast cells; adipose: A-MSCs. Scale bar $=200 \mu \mathrm{m}$. (b) The number of CD34-positive cells in corpus lutea (CL) in ovaries. The number of CD34positive cells per $1 \mathrm{~mm}^{2}$ of $\mathrm{CL}$ was examined. Significant differences between each character is represented by $\mathrm{a}, \mathrm{b}$ and $\mathrm{c}(P<0.05)$. Fibroblast: tail fibroblast cells; adipose: A-MSCs.

A-MSCs, tail fibroblast cells or saline solution were transplanted into left ovaries, and right ovaries served as noninjected side. Significant decline of CD34-positive cells was observed after CTX treatment when compared between control and CTX $(+)$ saline group (control: $699.8 \pm 69.4$; CTX-Ssline: $175 \pm 31.9$ ), showing that CTX treatment decreased angiogenesis (Figure $3 \mathrm{a}$ and $\mathrm{b}$ ). The numbers of CD34-positive cells in CTX-saline-, tail fibroblast- and A-MSC-transplanted groups were $171.8 \pm 31.7,178.8 \pm 47.0$ and $319.9 \pm 43.0$, respectively. The number of CD34-positive cells was increased significantly in A-MSC-transplanted group. Although the number of CD34-positive cells in A-MSC-transplanted group was not comparable to the CTX- untreated control group (A-MSC: $319.9 \pm 43.0$; control: $693.5 \pm 73.8$ ), these results clearly showed that A-MSC transplantation after CTX treatment induced angiogenesis in ovaries.

\section{The Total Number of Vesicular Follicles and Corpus Lutea were Increased in CTX-Treated Ovaries after MSC Transplantation}

The total numbers of follicles and corpus lutea in MSCtransplanted left ovaries after CTX treatment were divided by the numbers of follicles and corpus lutea in untreated right ovaries, and the values were compared. Morphologically healthy follicles were observed in A-MSC-transplanted 
$(-)$
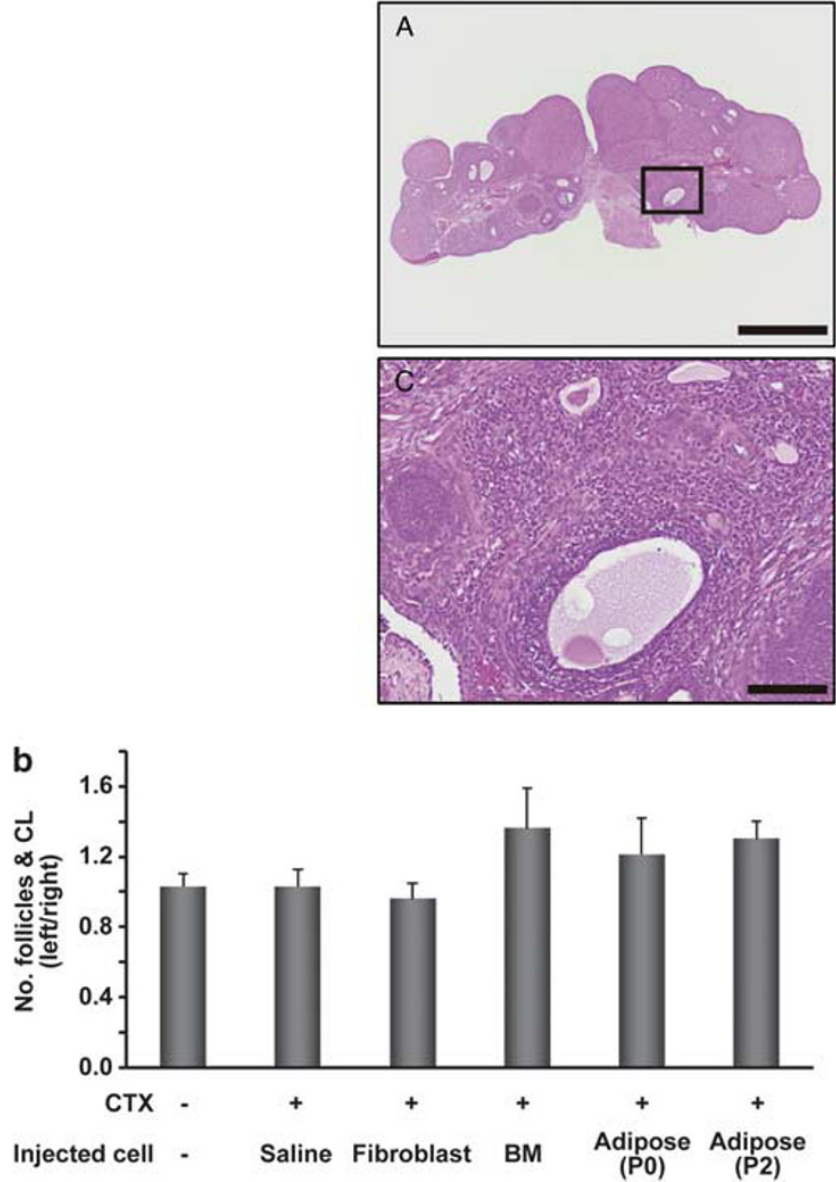

$(+)$
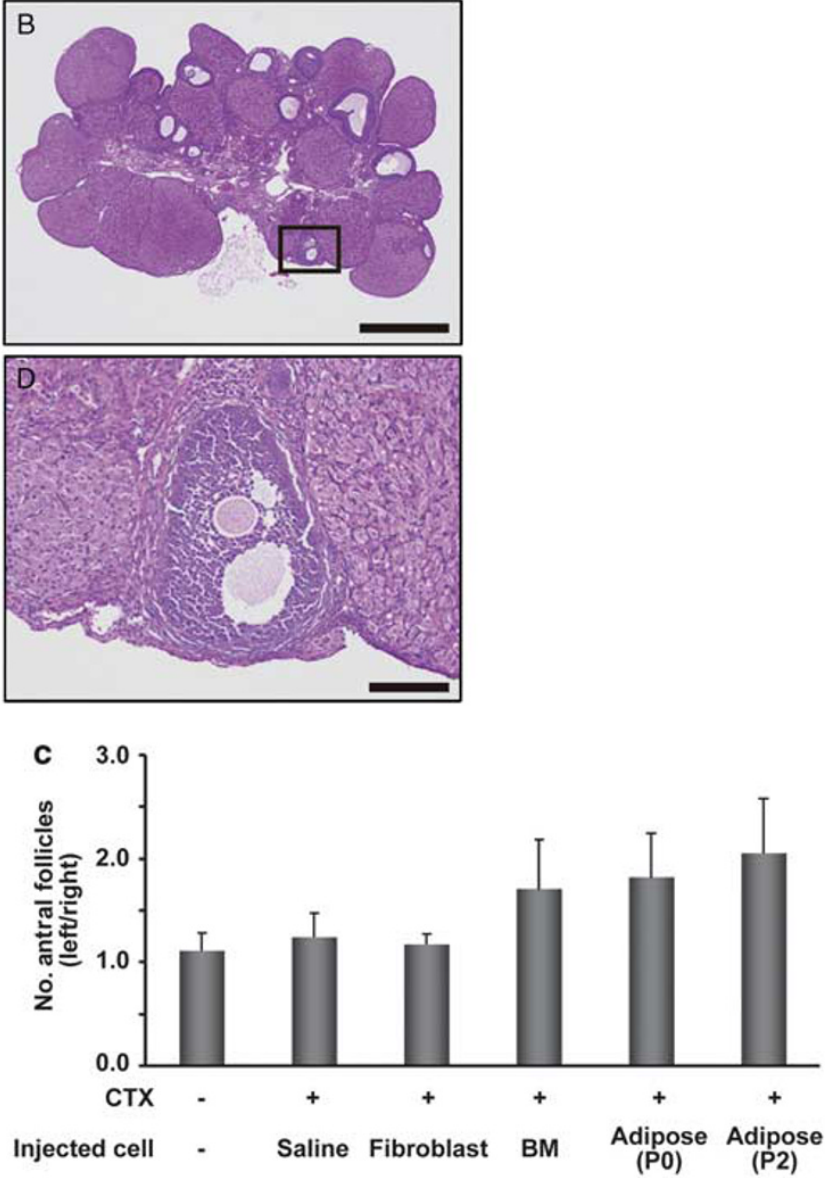

Figure 4 Analysis of ovaries after adipose-derived mesenchymal stem cell (A-MSC) transplantation. (a) Histological analysis of follicles in ovaries and after A-MSC transplantation. (A, C) A-MSC non-transplanted and (B, D) A-MSC transplanted. (A, B) Scale bar $=1 \mathrm{~mm}$ and (C, D) scale bar $=200 \mu \mathrm{m}$. (b) Ratio of number of follicles and corpus lutea $(\mathrm{CL})$ in MSC-transplanted left ovary vs MSC-non-transplanted right ovary. BM: bone marrow-derived MSCs (BM-MSCs); adipose: A-MSCs; fibroblast: tail fibroblast cells. (c) Ratio of number of antral follicles in MSC-transplanted left ovary vs MSC-nontransplanted right ovary. BM: BM-MSCs; adipose: A-MSCs; fibroblast: tail fibroblast cells.

ovaries (Figure 4a). The ratio of total numbers of follicles in A-MSC- (P0), A-MSC- (P2), BM-MSC- (P2), tail fibroblastand saline-transplanted left ovaries were $1.21 \pm 0.21$, $1.30 \pm 0.10,1.36 \pm 0.23,0.96 \pm 1.8$ and $1.03 \pm 0.10$, respectively, and the ratio of the numbers of vesicular follicles (antral follicles) in A-MSC- (P0), A-MSC- (P2), BM-MSC(P2), tail fibroblast- and saline-transplanted left ovaries was $1.81 \pm 0.43, \quad 2.05 \pm 0.53, \quad 1.70 \pm 0.48, \quad 1.17 \pm 0.10 \quad$ and $1.24 \pm 0.23$, respectively (Figure $4 \mathrm{~b}$ and $\mathrm{c}$ ). There were no significant differences between the groups; however, MSCtransplanted groups had a tendency to increase the follicle number.

\section{Functional Improvement and Safety in MSC- Transplanted Ovaries by Comparing Litters}

At 8 weeks after MSC transplantation into both of the ovaries, the female rats $(n=5)$ were housed in the same cages as male rats to promote natural mating. The resulting number of litters was compared. The gestation of the rats in the A-MSC-transplanted group were 21-22 days, which are normal values, and no cases of abnormal litter numbers, external deformities or abnormal growth after birth were observed (Figure 5a (A-F)). The average number of litters in the group of CTX-administered rats with decreased ovarian function and saline-injected ovaries (9.4) was significantly lower than that in the control group of CTX-non-administered rats (14.3). The number of litters in MSC-transplanted group was 12.8 for BM-MSCs and 13.6 for A-MSCs, and the number of litters in A-MSC-transplanted group was significantly higher than that in the saline-infused control group. Therefore, ovarian function can be improved by transplanting A-MSCs into the ovaries (Figure 5b). The F2 litters also had gestations of 21-22 days. In addition, no significant differences were seen among the groups, and no deformities or any serious adverse effects were seen (Figure 5c). 
a
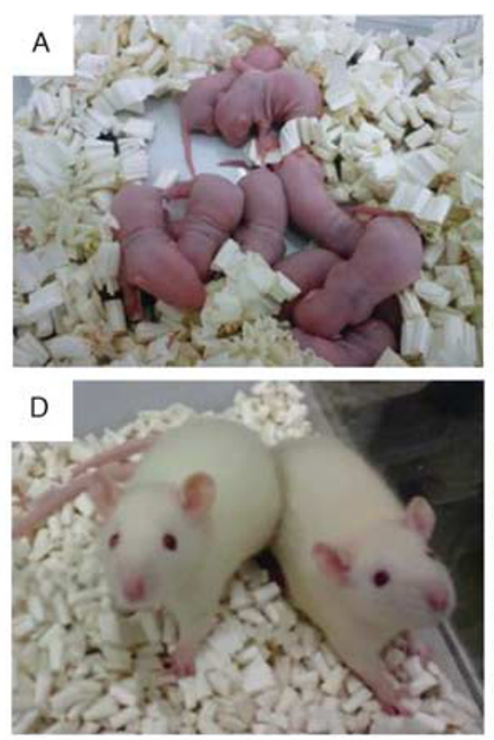

b

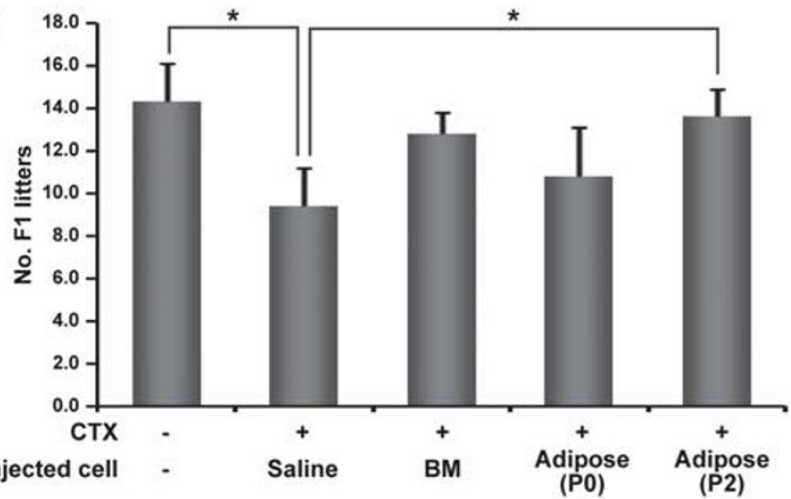

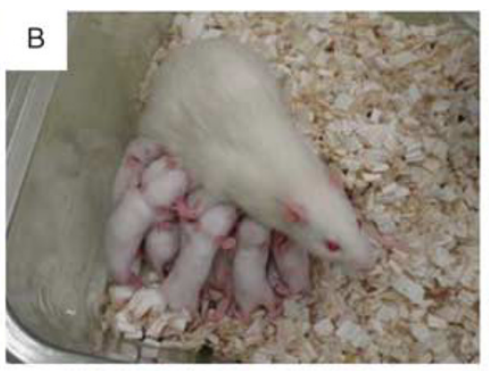
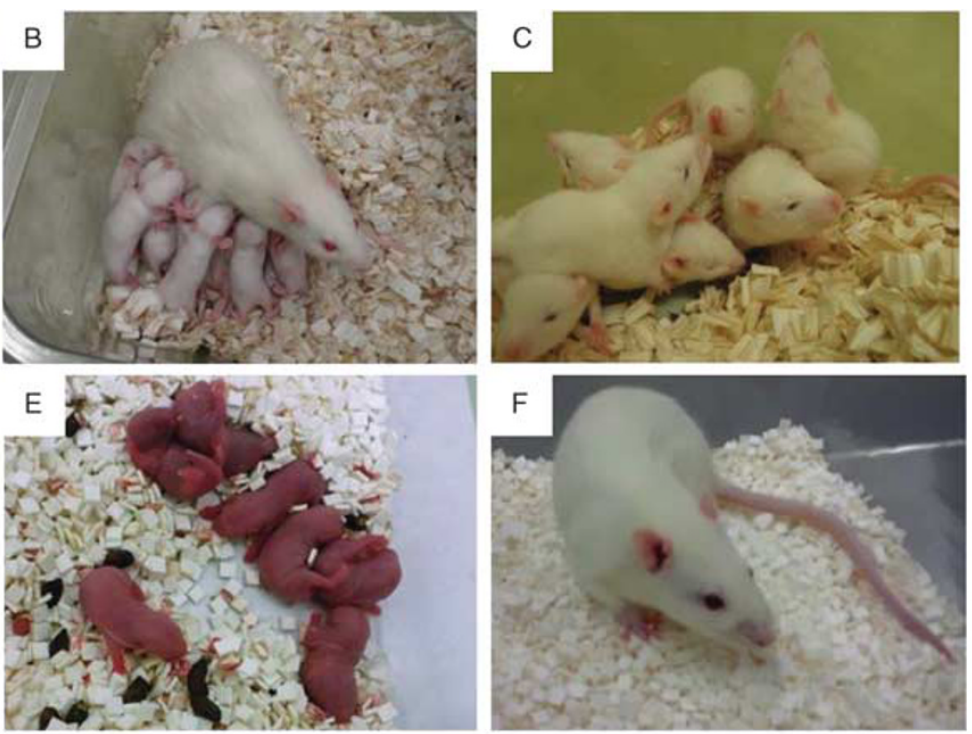

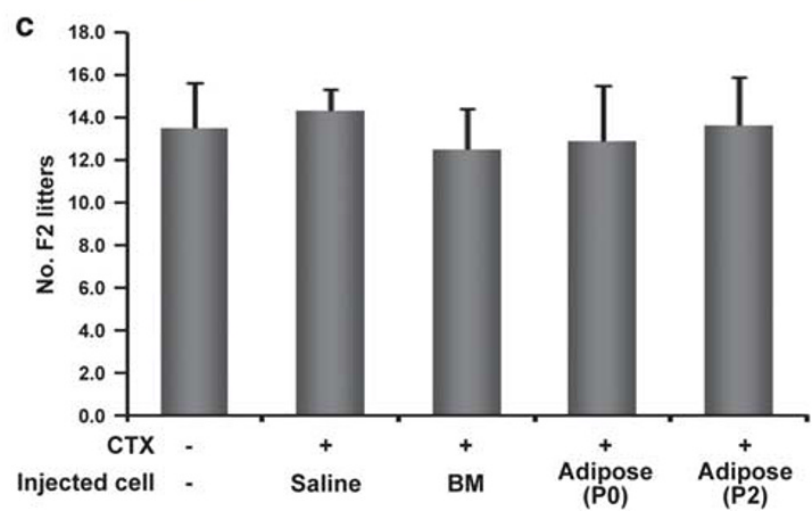

Figure 5 F1 litters and F2 litters obtained by mating after adipose-derived mesenchymal stem cell (A-MSC) transplantation into the ovary. (a) The photographs of F1 and F2 litters. (A) Immediately after birth (F1); (B) 1-week-old rats (F1); (C) 3-week-old rats (F1); (D) 5-week-old rats (F1); (E) immediately after birth (F2); and (F) 5-week-old rats (F2). (b) The number of F1 litters. BM: bone marrow-derived MSCs (BM-MSCs); adipose: A-MSCs $\left({ }^{*}\right.$ significantly different, $\left.P<0.05\right)$. (c) The number of F2 litters. BM: BM-MSCs; adipose: A-MSCs.

\section{Cytokine Secretion from A-MSCs}

The measurement of VEGF, IGF-1 and HGF concentrations in the A-MSC and tail fibroblast cell culture supernatant using EIA showed that A-MSCs secreted high level of humoral factors than fibroblasts. Significantly higher levels of VEGF, IGF-1 and HGF $(P<0.05)$ were secreted by A-MSCs (Figure 6a), compared with fibroblasts. No significant difference in estradiol levels was seen (Figure 6a).

\section{Cytokine Expression in Ovaries after A-MSC Transplantation}

The experiment described above revealed that A-MSCs secrete HGF, VEGF and IGF-1. Next, quantitative (q) RT-PCR and immunohistochemistry (IHC) were applied to examine whether A-MSCs secrete growth factors in ovarian tissues after transplantation. The ratio of mRNA expression of VEGF, HGF, IGF-1 and StAR in A-MSC-transplanted CTX $(+)$ ovaries to non-transplanted ovaries was $1.86 \pm 0.01$, $5.80 \pm 0.55, \quad 2.79 \pm 0.40$ and $2.89 \pm 0.27$, respectively
(Figure 6b). On the other hand, the ratio of VEGF, HGF, IGF-1 and StAR mRNA expression in tail fibroblast celltransplanted ovaries was $0.86 \pm 0.05,0.94 \pm 0.04,0.95 \pm 0.06$ and $0.88 \pm 0.03$, respectively. A-MSC-transplanted ovaries demonstrated significantly higher ratio of mRNA expression of these four genes. IHC studies for HGF, VEGF and IGF-1 in ovarian tissue revealed that expression of HGF, VEGF and IGF-1 proteins was frequently observed in the CTX-nontreated group. In contrast, in the CTX-treated group, decreased expression of these proteins was observed. In A-MSC-transplanted CTX $(+)$ ovaries, the expression of all the HGF, VEGF and IGF-1 proteins reached to levels to those seen in untreated ovaries (Figure 6c).

\section{Distribution of A-MSCs after Transplantation into the Ovaries}

Ovarian tissues were subjected to FISH staining. In the granulosa cells and corpus luteum, only female cells with XX karyotype labeled with Texas Red-conjugated X chromosome 
were detected, while A-MSCs were not found (Figure 6d (A and B)). Cells containing XY karyotype labeled with FITCconjugated Y chromosome, indicating male-derived A-MSCs, were observed only in thecal layer area (Figure $6 \mathrm{~d}(\mathrm{C})$ ). These results show that A-MSCs engraft in the supportive cells associated with follicular growth.

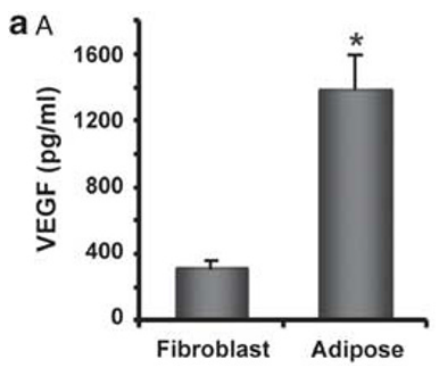

b
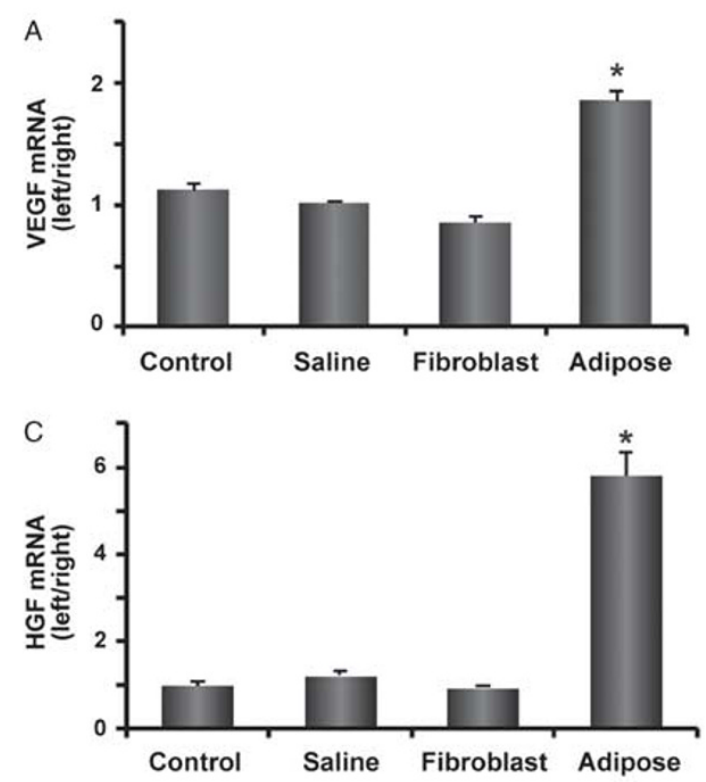

C

$\operatorname{CTX}(-)$

CTX (+) Adipose
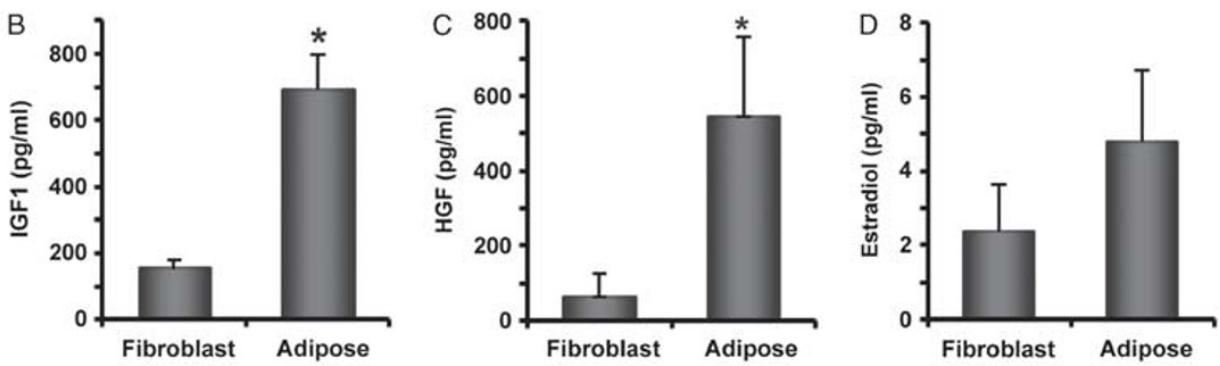

B
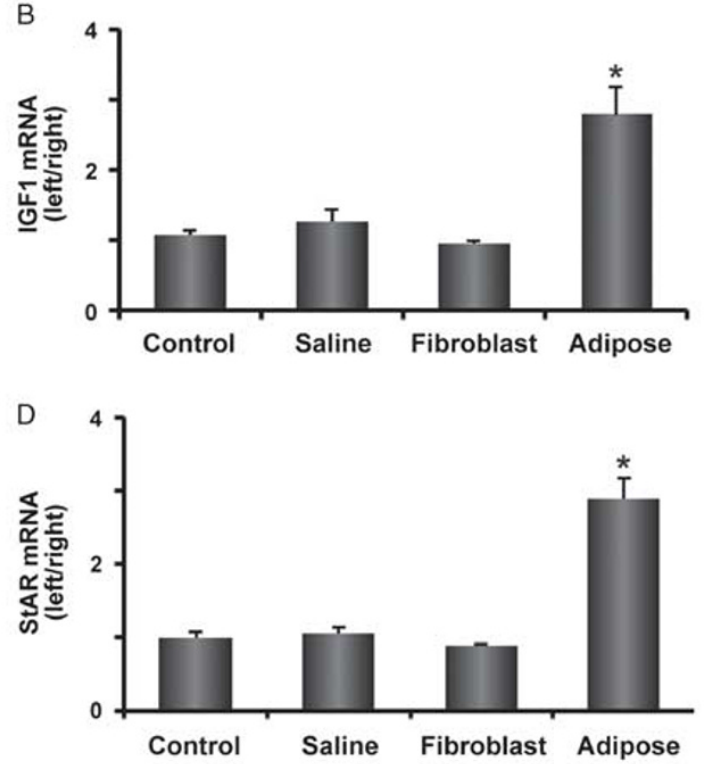

HGF
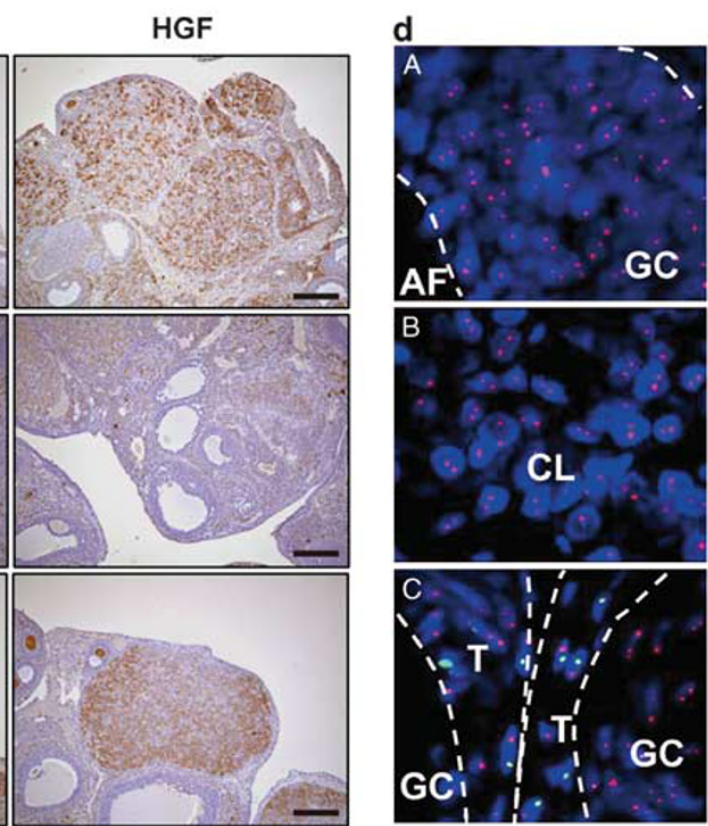


\section{Growth Factors Administration was Ineffective in CTX- Treated Mouse Ovaries}

ELISA showed that the secretion of VEGF, HGF and IGF-1 in mouse A-MSC conditioned media was $779.9 \pm 30.4$, $589.9 \pm 50.6$ and $150.9 \pm 22.3$, respectively (Figure 7a). A $1 \times$ dose and $10 \times$ doses of these three growth factors were determined based on ELISA results and were administered into CTX-treated left ovaries, and the ratio of the number of ovarian follicles in left ovaries to the right ovaries was evaluated. The established mouse A-MSCs were proved to retain MSC properties by FACS (Figure $7 \mathrm{~b}$ ). The higher ratio of the number of follicles was observed in $5 \times 10^{4}, 5 \times 10^{5}$ and $5 \times 10^{6}$ of A-MSC-transplanted group (2.36 \pm 0.54 , $1.93 \pm 0.20$ and $1.96 \pm 0.30$, respectively), showing that A-MSC transplantation is effective. However, some of the growth factor-administered group showed slight improvement in the follicular number (eg VEGF $1 \times$ dose: $1.38 \pm 0.20$; IGF- $11 \times$ dose: $1.37 \pm 0.29$ ), the results were not comparable to A-MSC-transplanted group (Figure 7c).

\section{DISCUSSION}

This study showed that the transplantation of A-MSCs into the ovary improved ovarian function, suggesting that this procedure may be useful in patients with ovarian failure. Considering future human clinical applications, the collection of BM-MSCs is problematic because of the invasive procedure. On the other hand, human abdominal subcutaneous adipose tissue aspiration, which is commonly used for cosmetic procedures the adipose discarded, could be used for MSC derivation in a procedure that is easy and less invasive. $^{24-27}$ Adipose-derived cells were first reported in 1964 (ref.28) and the use of adipose-derived MSCs has been considered, ${ }^{29}$ and the multi-potential differentiation of A-MSCs has also been well studied. ${ }^{30}$ Recently, it has been reported that not only subcutaneous but also visceral adipose tissues have A-MSC properties. ${ }^{31}$

We evaluated the effects on ovarian function after the transplantation of A-MSCs into ovaries in rats with ovarian failure. The transplantation of A-MSCs into the ovaries that show decreased ovarian function due to CTX administra$\operatorname{tion}^{32,33}$ results in the induction of angiogenesis and increased counts of corpora lutea and ovarian follicles and StAR mRNA expression, compared with ovaries that did not receive transplantations. In addition, the number of litters obtained by natural mating was significantly increased with A-MSC-transplanted ovaries compared with the nontransplanted group. To analyze the distribution of transplanted A-MSCs, male rat A-MSCs were transplanted into ovaries and examined by FISH (X- and Y-specific probes). The observations showed that there were no $\mathrm{XY}$ (male) cells in the ovarian follicles (granulosa cells) or corpus lutea and that the fibroblastic XY cells were distributed in thecal layer area (Figure 6d), which indicates that MSCs transplanted into the ovary may not differentiate directly into oocytes or granulosa cells, but may survive in the interstitium, playing important accessory roles in the microenvironment surrounding the oocytes in the ovary.

It has been demonstrated that human MSCs secreted variety of growth factors, such as IL-6, VEGF, IL-8, G-CSF, SCF, IL-11, IL-15, IL-10, PDGF-bb and bFGF. ${ }^{34-36}$ We focused on VEGF, HGF and IGF-1, which are known to affect follicular growth in ovaries. The secretion of these factors by rat A-MSCs was quantified by EIA. VEGF prevents damage to cumulus cells, reducing apoptosis in frozen-thawed rat cumulus cells when added in a culture medium. ${ }^{37}$ IGF-1 is also believed to suppress apoptosis and cause the proliferation of porcine cumulus cells. ${ }^{38} \mathrm{HGF}$ is expressed in cumulus cells and theca cells and shows an antiapoptotic effect on cumulus cells. ${ }^{39}$ Our EIA results clearly demonstrated that rat A-MSCs secrete higher level of these growth factors than tail fibroblast cells. We also observed that mRNA and protein expression of these factors were higher in A-MSC-transplanted ovaries than in fibroblast- or saline-treated transplanted ovaries. These results indicate that MSCs are secreted by these cytokines and MSC transplantation induces mRNA and protein expression of these factors for repairing damaged ovaries.

We next addressed whether administration of growth factor (s) alone show a beneficial effect in damaged ovaries by injecting VEGF, HGF and IGF into damaged ovaries and compared with those A-MSC-transplanted ovaries. A-MSCtransplanted ovaries revealed more restorative effects in terms of the number of follicles than ovaries treated with growth factors; nevertheless, some of them demonstrated a small recovery, indicating that not only VEGF, HGF and IGF-1 but also other growth factors secreted by A-MSCs may be needed for restoration of damaged ovaries. Taken together with our

Figure 6 Cytokine secretion from adipose-derived mesenchymal stem cells (A-MSCs), cytokine expression in A-MSC-transplanted ovaries and the localization of A-MSCs in ovaries after transplantation. (a) Cytokine secretion (vascular endothelial cell growth factor (VEGF), insulin-like growth factor-1 (IGF-1), hepatocyte growth factor (HGF) and estradiol) from A-MSCs. (A) VEGF; (B) IGF-1; (C) HGF; and (D) estradiol. Each cytokine was measured by enzyme immunoassay (EIA) analysis. Significantly higher levels of VEGF, IGF-1 and HGF $\left({ }^{*} P<0.05\right)$ were secreted from A-MSCs $(n=7)$, compared with fibroblasts $(n=9)$. No significant difference in estradiol levels was observed. Adipose: A-MSCs; fibroblast: tail fibroblast cells. (b) Quantitative real-time polymerase chain reaction (qRT-PCR) on ovaries after A-MSC and tail fibroblast cell transplantation. (A) VEGF; (B) IGF-1; (C) HGF; and (D) StAR. Adipose: A-MSCs; fibroblast: tail fibroblast cells (*significantly different, $P<0.05)$. (c) Immunohistochemistry (IHC) of cytokines (VEGF, IGF-1 and HGF) in ovaries after A-MSC transplantation. Top panels: sham operation; middle panels: cyclophosphamide (CTX) injected; bottom panels: CTX and A-MSC injected. BM: bone marrow-derived MSCs; adipose: A-MSCs. Scale bar $=200 \mu \mathrm{m}$. (d) Localization of A-MSCs after transplantation into ovaries by fluorescent in situ hybridization (FISH). Male A-MSCs were injected into ovaries and detected by FISH using the Y-chromosome-specific probe. Red: X chromosome conjugated with Texas Red; green: Y chromosome conjugated with FITC. (A) AF: antral follicles, GC: granulosa cells; (B) CL: corpus luteum; (C) T: thecal cells. Cells containing XY karyotype, indicating male-derived ASCs, were observed only in thecal layers. 

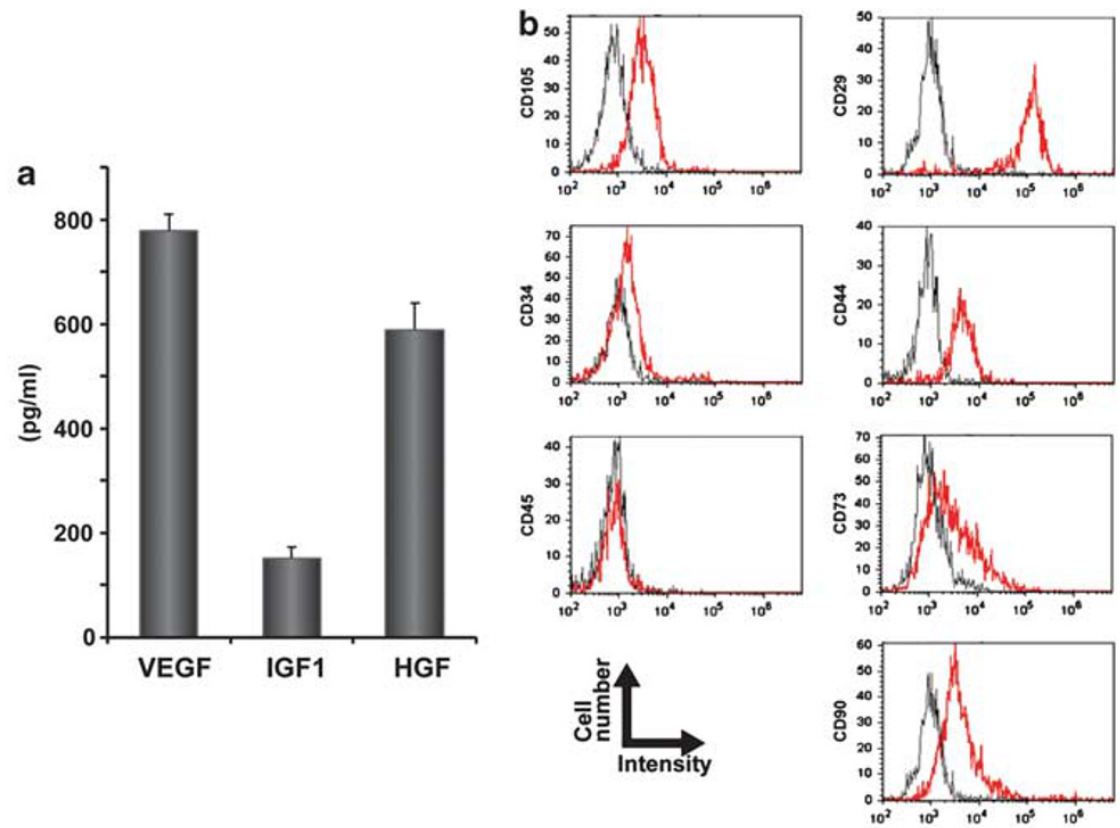

C

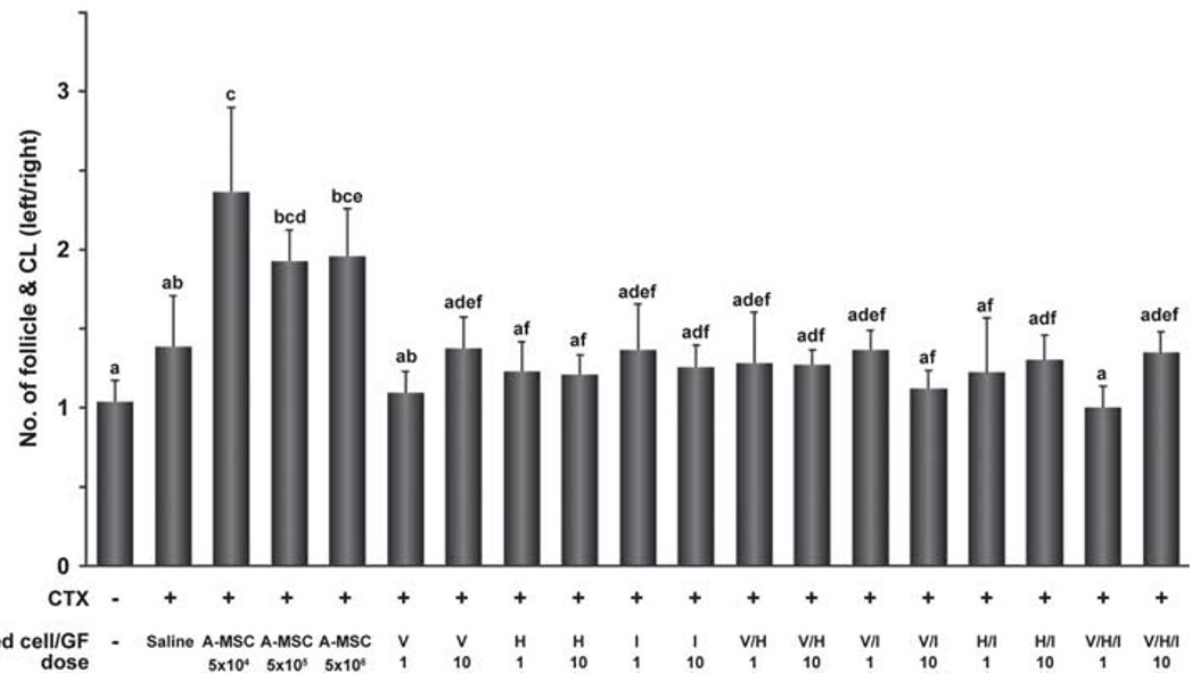

Figure 7 Growth factors administration into mouse ovaries. (a) Cytokine secretion from mouse adipose-derived mesenchymal stem cells (A-MSCs) measured by enzyme immunoassay (EIA). Secretion of mouse vascular endothelial cell growth factor (VEGF), hepatocyte growth factor (HGF) and insulin-like growth factor-1 (IGF-1) were measured by enzyme-linked immunosorbent assay (ELISA). (b) Fluorescence cell sorting (FACS) analysis of mouse A-MSCs stained with cell surface antigen markers of MSCs. (c) Ratio of number of follicles and corpus lutea (CL) in A-MSC and growth factortransplanted left ovary vs -non-transplanted right ovary. V: VEGF; H: HGF; I: IGF-1; 1: $10 \times$ dose; and 10: $10 \times$ doses. Significant differences between each character each character is represented by $a, b, c, d$, e and $f(P<0.05)$.

findings described in this study, it appears that a small population of transplanted A-MSCs was actually engrafted in the supportive cells associated with follicular growth in ovaries. Thus, we conclude that the possible mechanism by which A-MSCs participate in damaged ovary repair is by inducing angiogenesis and increasing the follicular growth related to paracrine activity.

The availability of stem cells isolated from autologous adipose tissues for tissue regeneration ${ }^{40}$ suggests that clinical applications of MSCs may be more advisable than those for ES or iPS cells in the field of regenerative medicine in the future.
Our findings in this study suggest potential therapeutic effects for ovarian dysfunction, including premature ovarian failure in cancer patients treated with $\mathrm{CTX},{ }^{41}$ breast cancer patients after chemotherapy ${ }^{42}$ and climacteric patients to improve their ovarian function by A-MSC transplantation.

\section{ACKNOWLEDGEMENTS}

We thank Minoru Ichinose, Nami Kawasaki and Jinji Mizuno for the help with the preparation of this manuscript.

\section{DISCLOSURE/CONFLICT OF INTEREST}

The authors declare no conflict of interest. 
1. Steptoe PC, Edwards RG. Birth after the reimplantation of a human embryo. Lancet 1978;2:366.

2. Palermo $\mathrm{G}$, Joris $\mathrm{H}$, Devroey $\mathrm{P}$, et al. Pregnancies after intracytoplasmic injection of single spermatozoon into an oocyte. Lancet 1992;340:17-18.

3. Trounson A, Mohr L. Human pregnancy following cryopreservation, thawing and transfer of an eight-cell embryo. Nature 1983;305: 707-709.

4. Zeilmaker GH, Alberda AT, van Gent I, et al. Two pregnancies following transfer of intact frozen-thawed embryos. Fertil Steril 1984;42: 293-296.

5. Cohen J, Simons RF, Edwards RG, et al. Pregnancies following the frozen storage of expanding human blastocysts. J In Vitro Fert Embryo Transf 1985;2:59-64.

6. Kuwayama $M$, Kato $\mathrm{O}$. All round vitrification of human oocytes and embryos. J Assist Reprod Genet 2000;17:477.

7. Kuwayama M, Vajta $G$, Kato $O$, et al. Highly efficient vitrification method for cryopreservation of human oocytes. Reprod Biomed Online 2005;11:300-308.

8. Cohen J, Elsner $\mathrm{C}$, Kort $\mathrm{H}$, et al. Impairment of the hatching process following IVF in the human and improvement of implantation by assisting hatching using micromanipulation. Hum Reprod 1990;5:7-13.

9. Handyside $\mathrm{AH}$, Kontogianni $\mathrm{EH}$, Hardy $\mathrm{K}$, et al. Pregnancies from biopsied human preimplantation embryos sexed by $\mathrm{Y}$-specific DNA amplification. Nature 1990;344:768-770.

10. Levin HS. Testicular biopsy in the study of male infertility: its current usefulness, histologic techniques, and prospects for the future. Hum Pathol 1979;10:569-584.

11. Schoysman R, Vanderzwalmen P, Nijs M, et al. Pregnancy after fertilisation with human testicular spermatozoa. Lancet 1993;342:1237.

12. Craft I, Bennett V, Nicholson N. Fertilising ability of testicular spermatozoa. Lancet 1993;342:864.

13. Tournaye H, Devroey P, Liu J, et al. Microsurgical epididymal sperm aspiration and intracytoplasmic sperm injection: a new effective approach to infertility as a result of congenital bilateral absence of the vas deferens. Fertil Steril 1994;61:1045-1051.

14. Evans MJ, Kaufman MH. Establishment in culture of pluripotential cells from mouse embryos. Nature 1981;292:154-156.

15. Thomson JA, Itskovitz-Eldor J, Shapiro SS, et al. Embryonic stem cell lines derived from human blastocysts. Science 1998;282:1145-1147.

16. Takahashi K, Yamanaka S. Induction of pluripotent stem cells from mouse embryonic and adult fibroblast cultures by defined factors. Cell 2006;126:663-676.

17. Nayernia K, Nolte J, Michelmann HW, et al. In vitro-differentiated embryonic stem cells give rise to male gametes that can generate offspring mice. Dev Cell 2006;11:125-132.

18. Nishiyama N, Miyoshi S, Hida N, et al. The significant cardiomyogenic potential of human umbilical cord blood-derived mesenchymal stem cells in vitro. Stem Cells 2007;25:2017-2024.

19. Okamoto K, Miyoshi S, Toyoda M, et al. 'Working' cardiomyocytes exhibiting plateau action potentials from human placenta-derived extraembryonic mesodermal cells. Exp Cell Res 2007;313:2550-2562.

20. Hida N, Nishiyama N, Miyoshi S, et al. Novel cardiac precursor-like cells from human menstrual blood-derived mesenchymal cells. Stem Cells 2008;26:1695-1704

21. Ikegami Y, Miyoshi S, Nishiyama N, et al. Serum-independent cardiomyogenic transdifferentiation in human endometrium-derived mesenchymal cells. Artif Organs 2010;34:280-288.

22. Tsuji H, Miyoshi S, Ikegami Y, et al. Xenografted human amniotic membrane-derived mesenchymal stem cells are immunologically tolerated and transdifferentiated into cardiomyocytes. Circ Res 2010;106:1613-1623.

23. Fu X, He Y, Xie $C$, et al. Bone marrow mesenchymal stem cell transplantation improves ovarian function and structure in rats with chemotherapy-induced ovarian damage. Cytotherapy 2008;10:353-363.

24. Housman TS, Lawrence N, Mellen BG, et al. The safety of liposuction: results of a national survey. Dermatol Surg 2002;28:971-978.
25. Schreml S, Babilas $P$, Fruth $S$, et al. Harvesting human adipose tissuederived adult stem cells: resection versus liposuction. Cytotherapy 2009;11:947-957.

26. Zuk PA, Zhu M, Mizuno $\mathrm{H}$, et al. Multilineage cells from human adipose tissue: implications for cell-based therapies. Tissue Eng 2001;7: 211-228.

27. De Ugarte DA, Morizono K, Elbarbary A, et al. Comparison of multilineage cells from human adipose tissue and bone marrow. Cells Tissues Organs 2003;174:101-109.

28. Rodbell M. Metabolism of isolated fat cells. I. Effects of hormones on glucose metabolism and lipolysis. J Biol Chem 1964;239:375-380.

29. Xie LW, Fang $H$, Chen AM, et al. Differentiation of rat adipose tissuederived mesenchymal stem cells towards a nucleus pulposus-like phenotype in vitro. Chin J Traumatol 2009;12:98-103.

30. Strem BM, Hicok KC, Zhu M, et al. Multipotential differentiation of adipose tissue-derived stem cells. Keio J Med 2005;54:132-141.

31. Baglioni S, Francalanci $M$, Squecco R, et al. Characterization of human adult stem-cell populations isolated from visceral and subcutaneous adipose tissue. FASEB J 2009;23:3494-3505.

32. Plowchalk DR, Mattison DR. Reproductive toxicity of cyclophosphamide in the $\mathrm{C} 57 \mathrm{BL} / 6 \mathrm{~N}$ mouse: 1. Effects on ovarian structure and function. Reprod Toxicol 1992;6:411-421.

33. Plowchalk DR, Mattison DR. Phosphoramide mustard is responsible for the ovarian toxicity of cyclophosphamide. Toxicol Appl Pharmacol 1991;107:472-481.

34. Choi MR, Kim HY, Park JY, et al. Selection of optimal passage of bone marrow-derived mesenchymal stem cells for stem cell therapy in patients with amyotrophic lateral sclerosis. Neurosci Lett 2010;472: 94-98.

35. Haynesworth SE, Baber MA, Caplan AI. Cytokine expression by human marrow-derived mesenchymal progenitor cells in vitro: effects of dexamethasone and IL-1 alpha. J Cell Physiol 1996;166:585-592.

36. Liu $\mathrm{CH}$, Hwang SM. Cytokine interactions in mesenchymal stem cells from cord blood. Cytokine 2005;32:270-279.

37. Shin SY, Lee JY, Lee $\mathrm{E}_{\text {, et }}$ al. Protective effect of vascular endothelia growth factor (VEGF) in frozen-thawed granulosa cells is mediated by inhibition of apoptosis. Eur J Obstet Gynecol Reprod Biol 2006;125: 233-238.

38. Mao J, Smith MF, Rucker EB, et al. Effect of epidermal growth factor and insulin-like growth factor I on porcine preantral follicular growth, antrum formation, and stimulation of granulosal cell proliferation and suppression of apoptosis in vitro. J Anim Sci 2004; 82:1967-1975

39. Uzumcu M, Pan Z, Chu Y, et al. Immunolocalization of the hepatocyte growth factor (HGF) system in the rat ovary and the anti-apoptotic effect of HGF in rat ovarian granulosa cells in vitro. Reproduction 2006;132:291-299.

40. D'Andrea F, De Francesco F, Ferraro GA, et al. Large-scale production of human adipose tissue from stem cells: a new tool for regenerative medicine and tissue banking. Tissue Eng Part C 2008;14 233-242.

41. Manger K, Wildt L, Kalden JR, et al. Prevention of gonadal toxicity and preservation of gonadal function and fertility in young women with systemic lupus erythematosus treated by cyclophosphamide: the PREGO-Study. Autoimmun Rev 2006;5:269-272.

42. Del Mastro L, Catzeddu T, Venturini M. Infertility and pregnancy after breast cancer: current knowledge and future perspectives. Cancer Treat Rev 2006;32:417-422.

This work is licensed under the Creative Commons Attribution-NonCommercial-No Derivative Works 3.0 Unported License. To view a copy of this license, visit http://creativecommons.org/licenses/by-nc-nd/ 3.0/ 